\title{
Analysis of sprites from video observations made by the Croatian Meteor Network
}

The Mining-Geology-Petroleum Engineering Bulletin UDC: 53.05

DOI: $10.17794 /$ rgn.2020.2.4

Original scientific paper

\author{
Marko Šegon'; Maria Vukić ; Damir Šegon \\ ${ }^{1}$ segi120@gmail.com (Astronomical Society “Istra” Pula, Pula, Croatia, mag.phys.) \\ ${ }^{2}$ vukic.maria@gmail.com (Astronomical Society "Istra” Pula, Pula, Croatia, mag.phys.) \\ 3damir@astro.hr (Astronomical Society “Istra” Pula, Pula, Croatia)
}

\begin{abstract}
Sprites are optical phenomena belonging to the category of transient luminous events. They were observed using cameras of the Croatian Meteor Network. The sprite images extracted from the recordings from cameras located in Rijeka and Višnjan were analysed using two methods. Sprites recorded on the night of 2017/05/31 at 21:46:18.781 and 22:03:27.299 only from the camera in Rijeka were analysed using the single-station analysis method. This method works on the assumption that sprites occur directly above the parent lightning and uses the lightning strike location provided by the Blitzortung website together with camera recordings from one station to make the spatial positioning of the sprite possible. Sprites recorded on the night of 2017/05/31 at 21:57:44.376 and 22:07:16.440 from both cameras in Rijeka and Višnjan were analysed using the double-station analysis method, which is based on the lines of sight method. Both double-station sprites were also analysed using the single-station analysis method. The resulting heights and lateral distances were compared. It was concluded that this method of single-station analysis may provide a good estimate of the sprite location in case of small lateral distances between the sprite and parent lightning, while in other cases, errors may be significant. The double-station analysis method is preferred whenever possible, as it is mathematically exact and the errors arising from it depend only on the quality of the observation data.
\end{abstract}

Keywords:

sprites, lightning, transient luminous events.

\section{Introduction}

Optical phenomena that occur above the clouds during thunderstorms are called transient luminous events (TLEs). They are divided into several categories, characterized by their distinctive colour, shape and size. The categories are sprites, blue jets, elves, gigantic jets, etc. (Mlynarczyk et al., 2015). Most common type of all are sprites, which is a manifestation of electrical breakdown of the mesosphere at an altitude between 40 and $90 \mathrm{~km}$ (Sentman et al., 1995) and last 10 to $100 \mathrm{~ms}$ (Heavner et al, 2000). Studies have shown that more than $90 \%$ of them were found in clusters (Bór, 2013). They are observable from space, aircrafts, as well as from the ground. The sprite's body is the brightest part of the sprite and previous studies have shown that above and below the body some additional features may appear such as tendrils, glows, puffs, beads and spots (Bór, 2013). Structures such as glows, beards, and spots can be found anywhere on the body of a sprite while puffs are located above and tendrils are located below the

Corresponding author: Marko Šegon

segi120@gmail.com body (Stanley et al. 1999; Stenbaek-Nielsen et al. 2000; Gerken et al. 2003; Stenbaek-Nielsen et al., 2008; Hardman et al., 2000). It has been shown that upper and lower extremities in height can extend above $95 \mathrm{~km}$ and below $40 \mathrm{~km}$ (Sentman et al., 1995; Wescott et al., 1998).

Sprites often start as one channel that later branches and, according to their final structure, they may be classified into columns, wishbones and trees, angel sprites, carrots, and other sprite forms (Bór, 2013). Most sprites are classified into column and carrot types. A column sprite is a bright, vertically aligned, elongated lightemitting column, the diameter of which ranges from tens of meters to a few hundred meters at 60 to $85 \mathrm{~km}$ altitude. The reported length of the columns ranges from 10 to $15 \mathrm{~km}$ in most cases (Bór, 2013). They have the simplest shape and are easily recognizable. Carrot sprites are considerably thicker than columns. Their body is wider in the upper part and it narrows as height decreases. The upper, broader area is brighter and is called the head that is usually at altitudes of 80 to $90 \mathrm{~km}$. The most significant difference between column and carrot types is that the electric discharge fronts in column sprites propagate exclusively downwards while fronts in the 

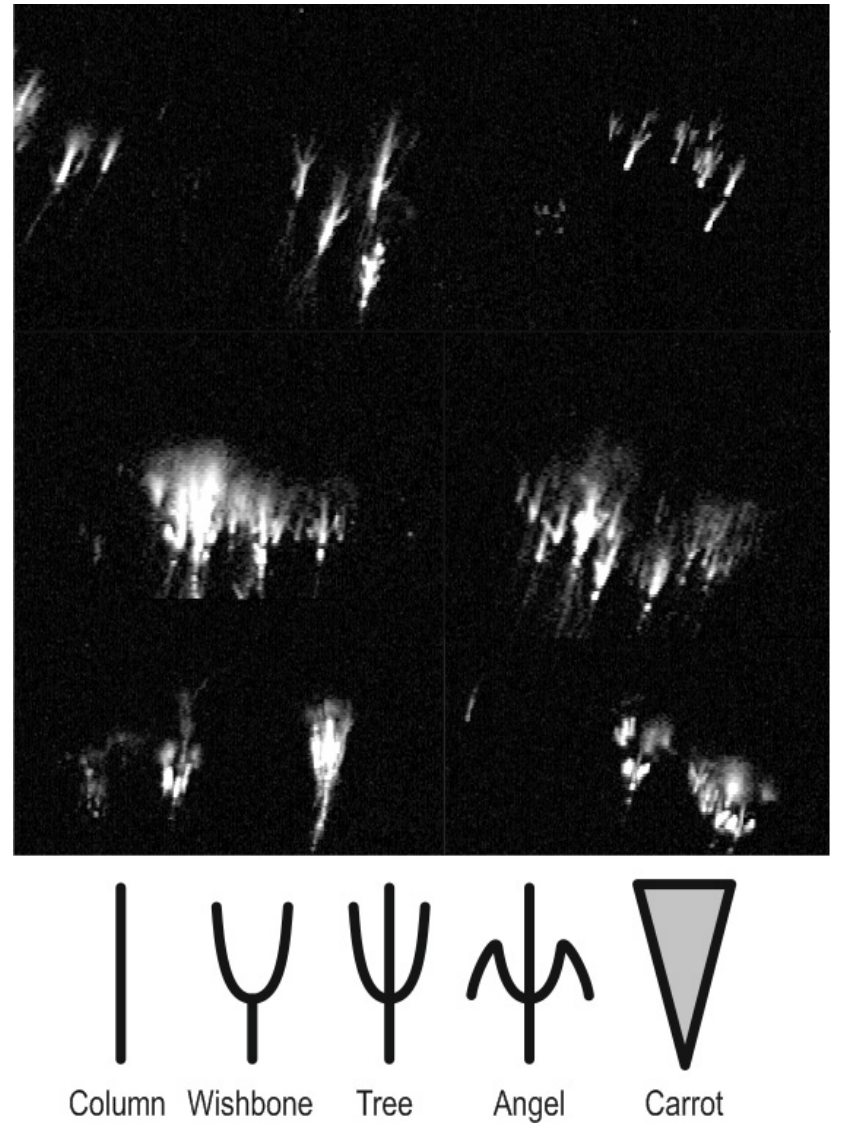

Figure 1: Sample of sprites captured by camera Rijeka_A on the night of 2017/05/31. Suggested shapes adopted from (Bór, 2013).

carrot category shoot upwards through the propagating channels (Malagon-Romero et al. 2020). Another type are wishbone sprites, which are usually V-shaped. Yshaped sprites are classified as trees or, at times, as wishbones for simplicity.

Figure 1 shows sample sprite images from the night of May 31 ${ }^{\text {st }}, 2017$ captured by a camera in Rijeka (above), and the characteristic form of sprite bodies adopted from (Bór, 2013; below). Note that a sprite's shape cannot always be associated to a single category as proposed but is often a combination of two or more.

The goal of this paper is to analyse sprites captured using cameras of the Croatian Meteor Network. The main goal of the analysis is to compare the calculated sprite heights with heights determined by other authors, as well as to determine the distance and time delay of the sprite from its parent lightning.

\section{Methods and data}

Video samples from the Croatian Meteor Network $(\mathrm{CMN})$ cameras located at Rijeka and Višnjan were used for the analysis. Two different methods were used to analyse the observed sprites. Hereafter, the sprites recorded from only one location are referred to as single- station sprites, while sprites recorded from two stations are referred to as double-station sprites.

The Croatian Meteor Network project was established during 2007, as described in literature (Andreić et al., 2008). It has been developing from year to year, both in terms of hardware used for video capture and software for meteor detection. Images used in this work were captured from interlaced video streamed from Sony ICX673 based cameras at $576 \times 720$ resolution, from camera stations in Višnjan (geographical longitude 13,721672, geographical latitude 45,275964, at a height over mean sea level of 218 meters) and Rijeka (geographical longitude 14,482893, geographical latitude 45,325099, at a height over mean sea level of 210 meters). Cameras were equipped with $4 \mathrm{~mm} \mathrm{~F} / 1.2 \mathrm{~mm}$ IR corrected lenses providing an effective field of view of $64 \times 48^{\circ}$.

The analysis was done using the programs CMN BinViewer (Vida et al., 2014), Adobe Photoshop, AstroImageJ, a $\mathrm{C}++$ program for calculating the spatial position of the points of interest, a python program for doublestation analysis, and Google Earth for the visual representation of the initial data and results. The application of each of those tools will be explained in the following sections.

The single-station sprite analysis was carried out using Blitzortung project data from the LightningMaps page which provides information on the timing and placement of lightning strikes. As the sprite formation is considered to be above the lightning strike, the lightning data, recorded at the same time as the sprite was recorded, served as the starting point for the spatial localization of the points of interest.

This method can be used to determine the $3 \mathrm{D}$ position of a sprite. However, it only works on the assumption that the sprite is situated exactly above the lightning, which, as will be seen later, is not always the case.

Further complications arise as, in most cases, it is unclear which lightning is responsible for which sprite. Often, multiple lightning strikes are detected at the same second in which the sprite appeared. The assumption that the lightning most closely matching the time and direction of the sprite is the one generating the sprite may not always be correct. The double-station analysis uses footage of the same sprite captured from cameras stationed in Rijeka and Višnjan. Here, the corresponding lightning is of no interest, seeing as the location of the sprite can now be calculated using data from the two stations.

\subsection{Image selection and preprocessing}

The CMN cameras in most cases work at 25 frames per second, producing an interlaced stream of frames. A deinterlaced image extracted from a single frame represents an odd or even field's image resulting in an actual image rate of 50 fields per second. This means that the cameras capture a frame every 0.04 seconds. Then, every 256 frames (10.24 seconds) are stacked together to form a single image. 


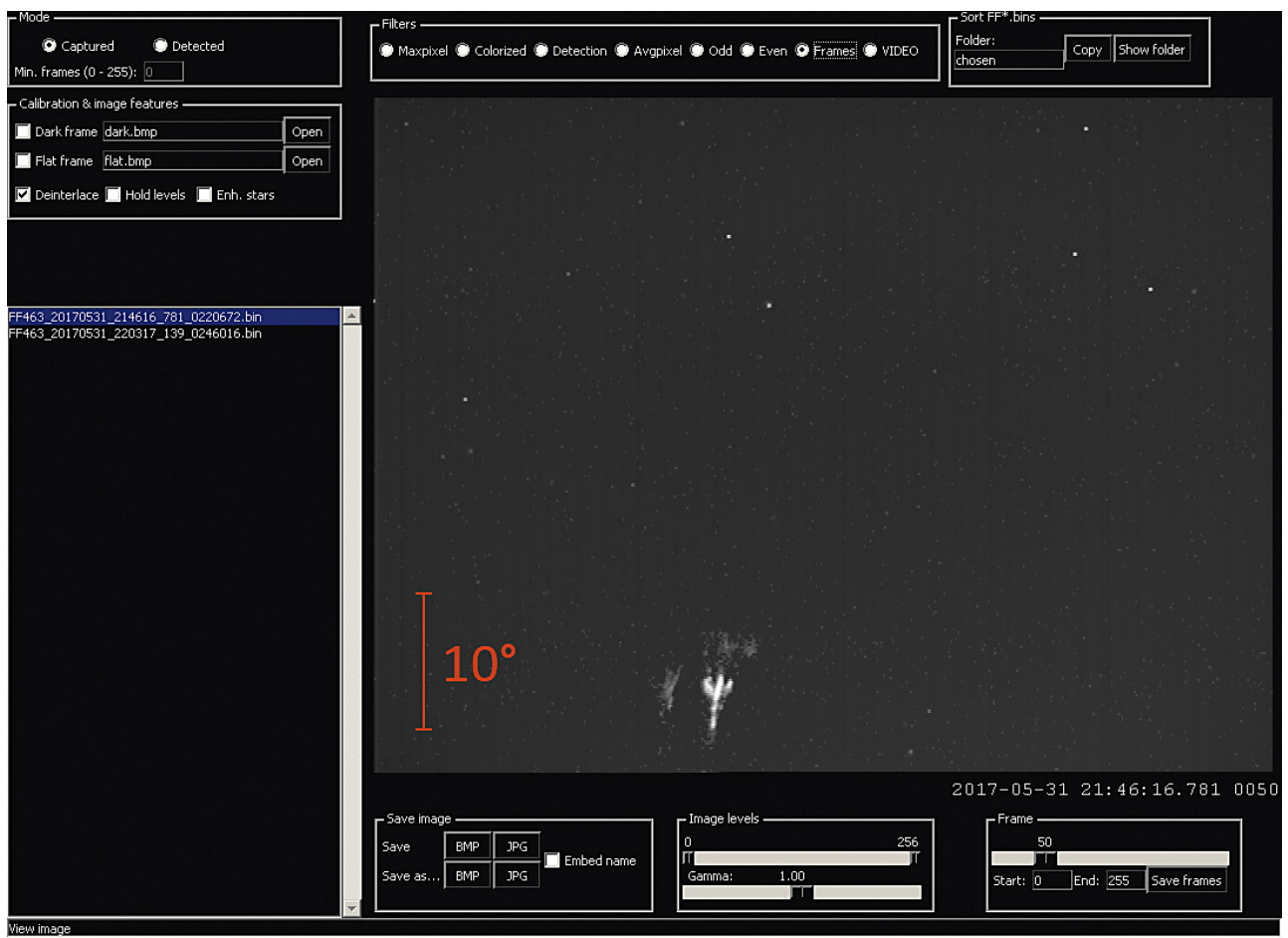

Figure 2: CMN BinViewer program

Camera shots are saved in BIN (binary) format, and it is possible to view and process them as in Figure $\mathbf{2}$ using CMN BinViewer (Šegon, 2009). The program allows the user to adjust the contrast of the recordings, view individual frames, extract even and odd fields, differently colour individual fields or apply other filters and options. In this analysis, the deinterlace option was used to view both, even and odd fields. The image was saved in BMP (bitmap) format to simplify further processing.

As previously mentioned, the duration of sprites can vary from a few to a few hundred milliseconds, which means that they appear on one, or less frequently, two frames. Using CMN BinViewer, the frames containing sprites were selected for further analysis. Here, the number of the frame containing the sprite is important for determining the exact time of the sprite appearance. Time is a parameter important for both the sprite location calculation, as well as selecting the corresponding lightning.

Images are saved in a "YYYY_MM_DD_HH_MM SS_SSS" name format, so that, for example, a file with the name 20170531_215400_905 would represent a stacked image beginning at $\overline{2017 / 05 / 31,21: 54: 00.905}$ (frame 0) and ending at 2017/05/31, 21:54:11.145 (frame $255)$. To calculate the exact time of the sprite occurrence, the number of the frame containing the sprite is multiplied by 0.04 seconds and then added to the time in the file name.

\subsection{Selection of key points}

Images in BMP format obtained from CMN BinViewer were processed in an image editing software

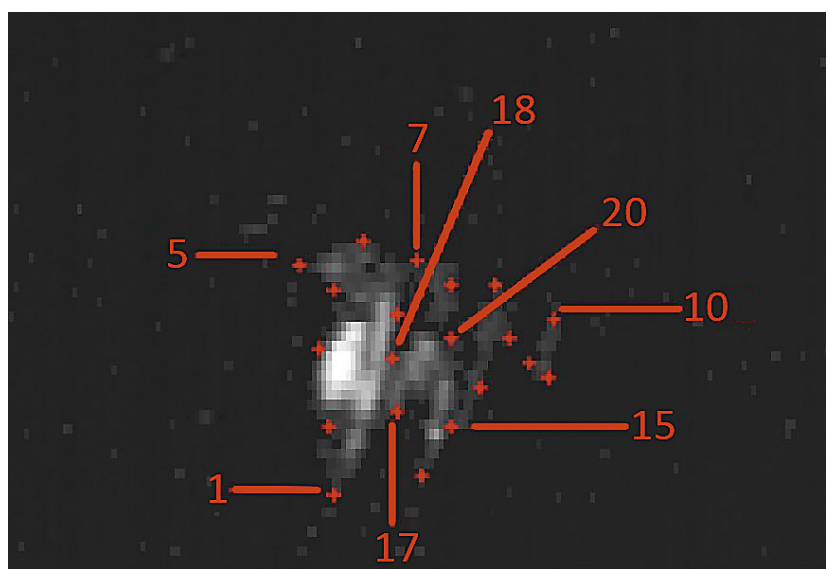

Figure 3: Preparation of the image for processing and selection of key points

(such as Adobe Photoshop or MS Paint). The program was used to manually mark characteristic points of the sprite, as displayed in Figure 3, and the corresponding coordinates would later be read in the AstroImageJ program.

For single-station sprite analysis, the points of interest were the leftmost, the rightmost, the top and the bottom point of the sprite. Those were later used to calculate the height and width of the sprites.

Here, a rough estimate of the points is considered fine for comparison with other authors, as the heights and widths vary heavily from sprite to sprite, and the singlestation analysis has an implicit error arising from the wrong assumption that the sprite is located exactly above the lighting. 


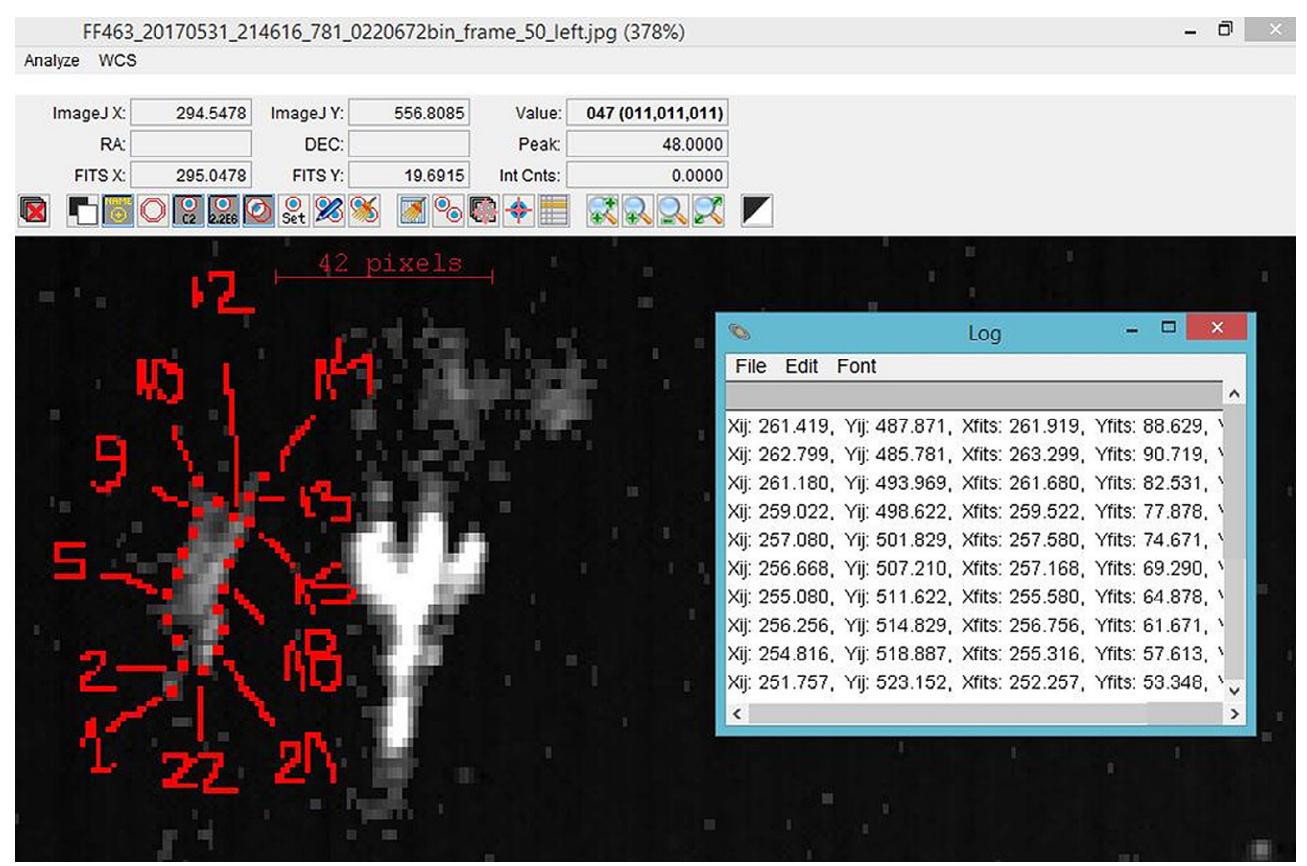

Figure 4: The selection of points in AstroImageJ for one of the detected sprites

For double-station sprites, the points were chosen to describe the sprite edges and it was very important to choose the same points of the sprite on both the image from the Višnjan camera and Rijeka camera in order to obtain a good spatial triangulation later. Also, a rough description of the edges of the sprite was later used to make a $3 \mathrm{D}$ representation of the sprite with Google Earth.

\subsection{Extraction of positions of key points}

Figure 4 shows how the selected points were later processed in the AstroImageJ program. The program loads the edited images with the points of interest in BMP format. Next, the marked points are manually selected, and the program returns their $\mathrm{X}$ and $\mathrm{Y}$ values as output. Even though a rough estimate of the position of the points is fine as mentioned before, in order to reduce the error, all the points were selected two times and averaged out. In order not to mix up which value corresponds to which point; some points were numerated on the images beforehand.

\section{4. $3 D$ position from single-station}

The $\mathrm{C}++$ program named CMN_SpriteHeight_TLeSortGeocentric AIJ uses two files. The first one contains $\mathrm{X}$ and $\mathrm{Y}$ values of the measured points obtained from AstroImageJ, the data of the corresponding lightning, and the time of detection. The second file contains camera orientation data and data needed for the correction of optical distortion, as well as the geographical coordinates of the station from which the sprite was detected.

Since transformations of the coordinate systems and spatial localization cause problems in both accounts, the basic elements of this program are based on a program used for meteor analysis. The details on the procedure may be found in literature (Šegon, 2009).

Executing the program will create a file with information containing the geocentric $\mathrm{X}, \mathrm{Y}, \mathrm{Z}$ coordinates, longitude, latitude, right ascension, declination and height of the selected points of the observed sprite. This is the last step in the program calculation for the single-station sprites.

Thereafter, the width of the sprites is simply determined from the distance between two 3D points. As heights of individual points are now known, it only remains to find the highest and the lowest points and to calculate the length of the sprite (which is, obviously, just the difference between the two).

\subsection{D position from double-station}

Double-station sprites require further analysis. For this part of the calculation, no lightning data was necessary. The triangulation was done with a python program provided by Denis Vida. The main working principle of the program is using the lines of sight method to calculate the spatial position of the sprite.

Here, the lines of sight method is used to find a point in 3D space. Since the same point of a sprite is observed from two stations simultaneously, the point at which the distance between the lines of sight of both stations is minimal is calculated. The desired $3 \mathrm{D}$ point is calculated as the mid-point between the closest points on the two lines of sight.

For this reason, the same points of the sprite were selected on images captured from both cameras as previously explained in the text. The details of the method are 
explained in (Borovička, 1990), simplified by the fact that only a single point position is being estimated.

The obtained result is a 3D location of the sprite obtained by comparing information from two separate stations. This provides a much smaller margin of error than the method used for single-station analysis, as it does not need to assume that the sprite is situated exactly above the lightning.

\subsection{Visualization}

After obtaining data on a lightning location and calculating the positions of single-station and double-station
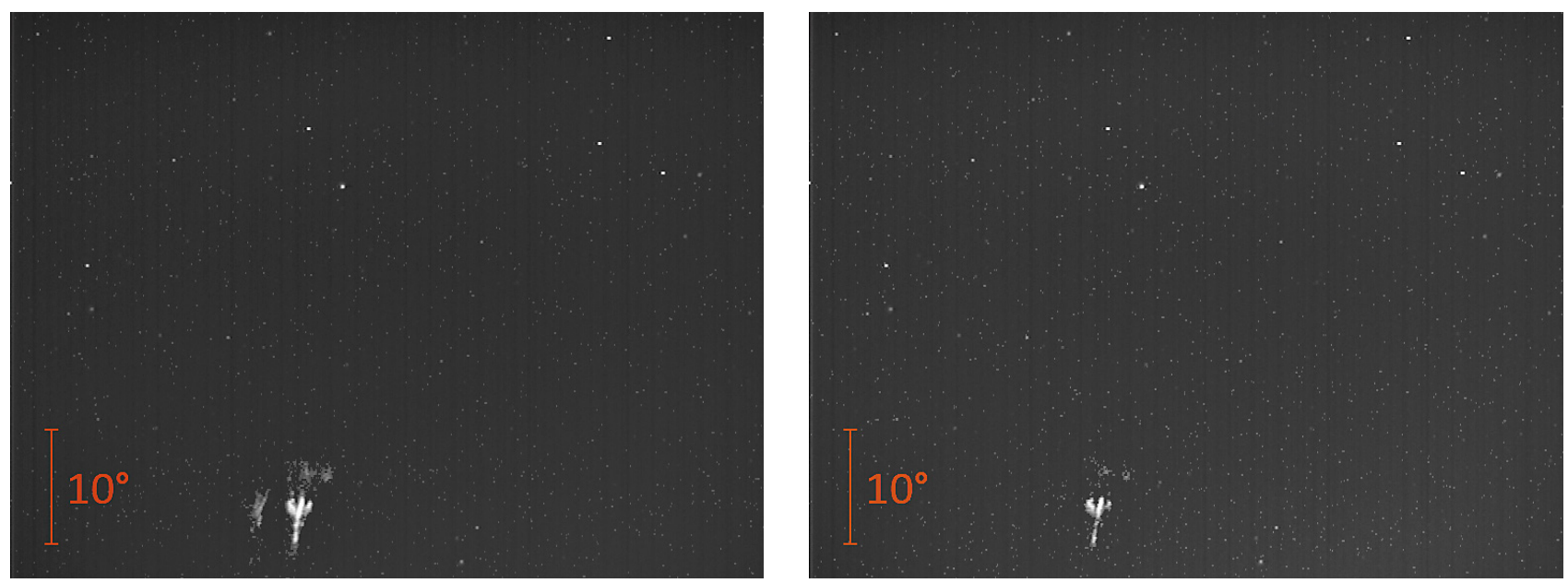

Figure 5: Sprites captured on 2017/05/31, at 21:46:18.781 on frames 50 and 51

Table 1: Data for sprites captured on 2017/05/31, at $21: 46: 18.781$ on frames 50 and 51

\begin{tabular}{|l|l|l|l|}
\hline SPRITE & Frame 50 left & Frame 50 right & Frame 51 \\
\hline width $/ \mathrm{km}$ & $2.47 \pm 0.03$ & $5.31 \pm 0.06$ & $5.02 \pm 0.02$ \\
\hline height $/ \mathrm{km}$ & $10.70 \pm 0.03$ & $22.30 \pm 0.06$ & $21.17 \pm 0.03$ \\
\hline $\begin{array}{l}\text { beginning } \\
\text { height } / \mathrm{km}\end{array}$ & $59.77 \pm 0.05$ & $56.84 \pm 0.02$ & $58.01 \pm 0.02$ \\
\hline $\begin{array}{l}\text { ending } \\
\text { height } / \mathrm{km}\end{array}$ & $70.47 \pm 0.02$ & $79.14 \pm 0.04$ & $79.17 \pm 0.01$ \\
\hline
\end{tabular}

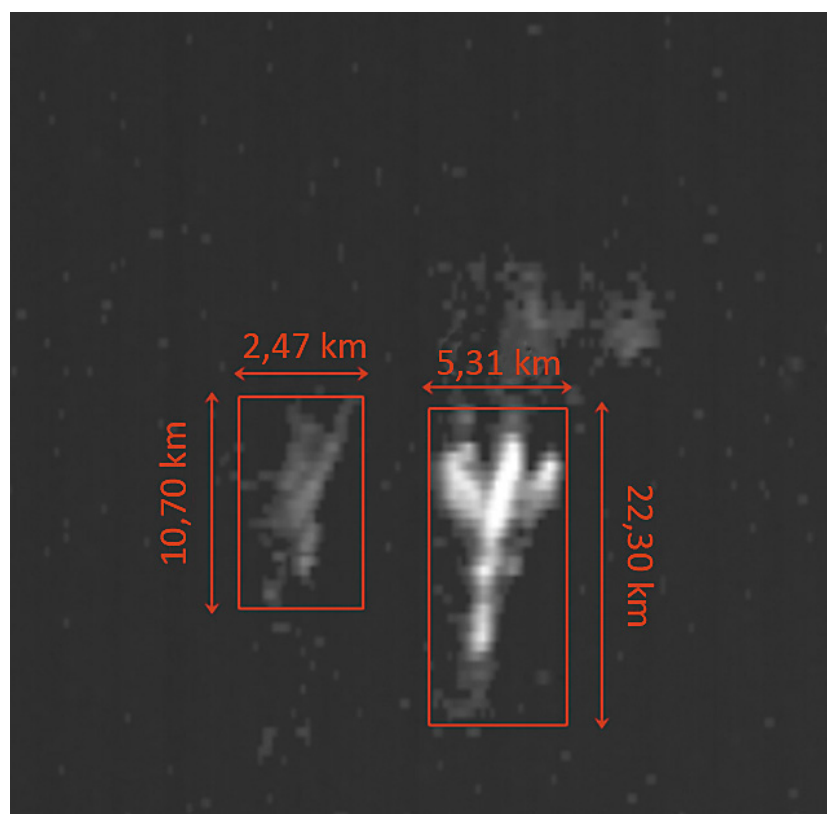

sprites, a good visual representation of the results was needed to comprehend them more easily. For that, Google Earth was used.

The locations of lightning strikes which occurred in the same minute as the sprite were mapped, as well as the location of the sprites. The data can be entered manually (point by point) in Google Earth or edited in the KML file (Google Earth file).

To minimise time consumption and the possibility of errors, the python program was modified to create a file

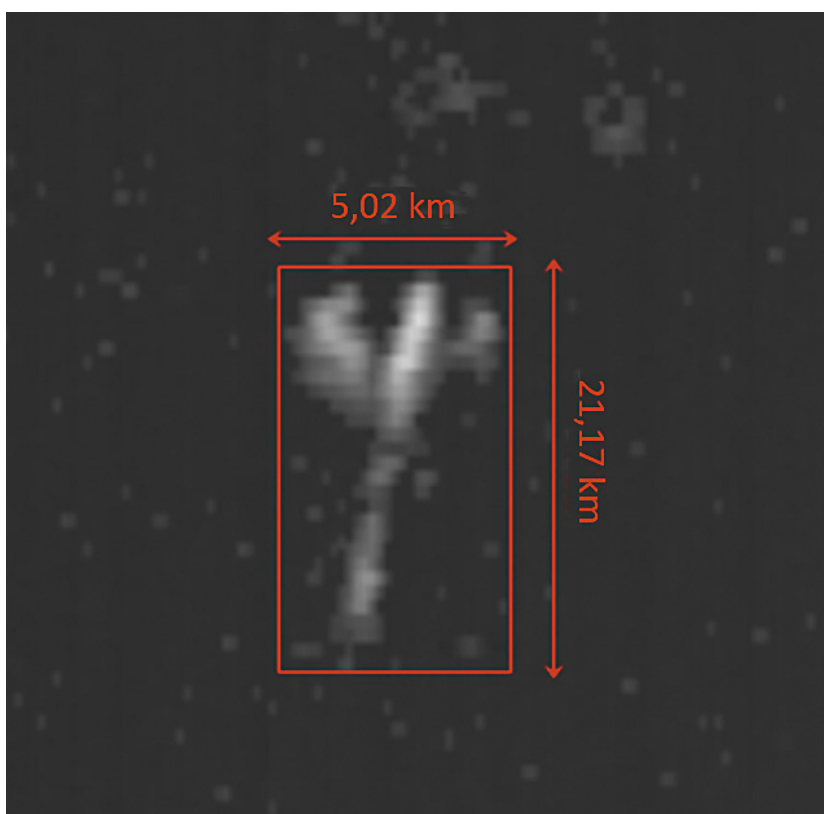

Figure 6: Dimensions of the sprites captured on 2017/05/31, at 21:46:18.781 on frames 50 and 51 

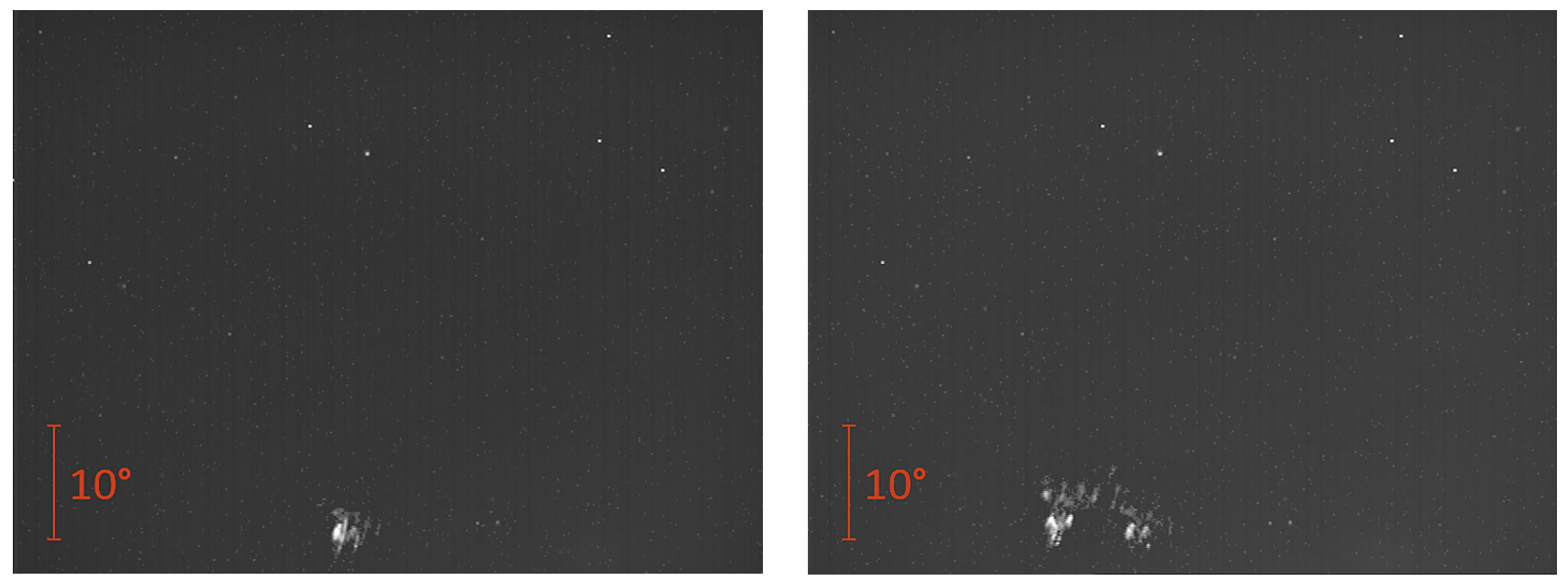

Figure 7: Sprites captured on 2017/05/31, at 22:03:27.299 on frames 254 and 255

Table 2: Data for sprites captured on 2017/05/31, at 22:03: 27.299 on frames 254 and 255

\begin{tabular}{|l|l|l|l|}
\hline SPRITE & Frame 254 & Frame 255 left & Frame 255 right \\
\hline width $/ \mathrm{km}$ & $12.87 \pm 0.08$ & $14.91 \pm 0.11$ & $13.56 \pm 0.08$ \\
\hline height $/ \mathrm{km}$ & $13.81 \pm 0.08$ & $20.19 \pm 0.27$ & $18.43 \pm 0.11$ \\
\hline $\begin{array}{l}\text { beginning } \\
\text { height } / \mathrm{km}\end{array}$ & $61.98 \pm 0.37$ & $60.72 \pm 0.36$ & $63.14 \pm 0.62$ \\
\hline $\begin{array}{l}\text { ending } \\
\text { height } / \mathrm{km}\end{array}$ & $75.79 \pm 0.65$ & $80.91 \pm 0.62$ & $81.56 \pm 0.48$ \\
\hline
\end{tabular}

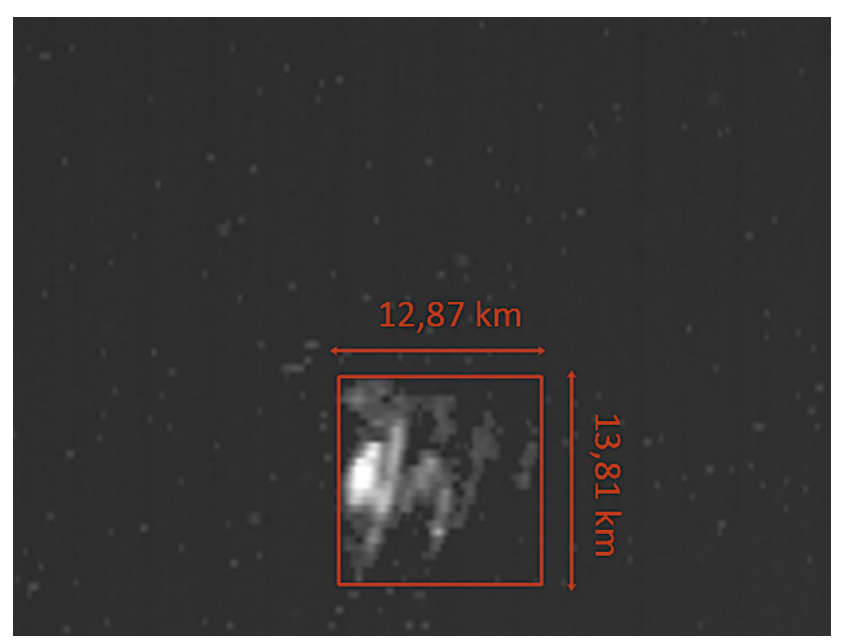

of two 3D points formula. Due to the simplicity of this calculation and a small number of sprites analysed, Microsoft Office Excel was used for this step.

In the future, when a bigger number of sprites are available for analysis, this part will most likely be automated. It must be pointed out that the leftmost and rightmost points of a sprite do not generally describe the width of the sprite well, as they could be diagonally positioned in regard to the sprite. To avoid such errors, those points were chosen by hand. As the widths vary

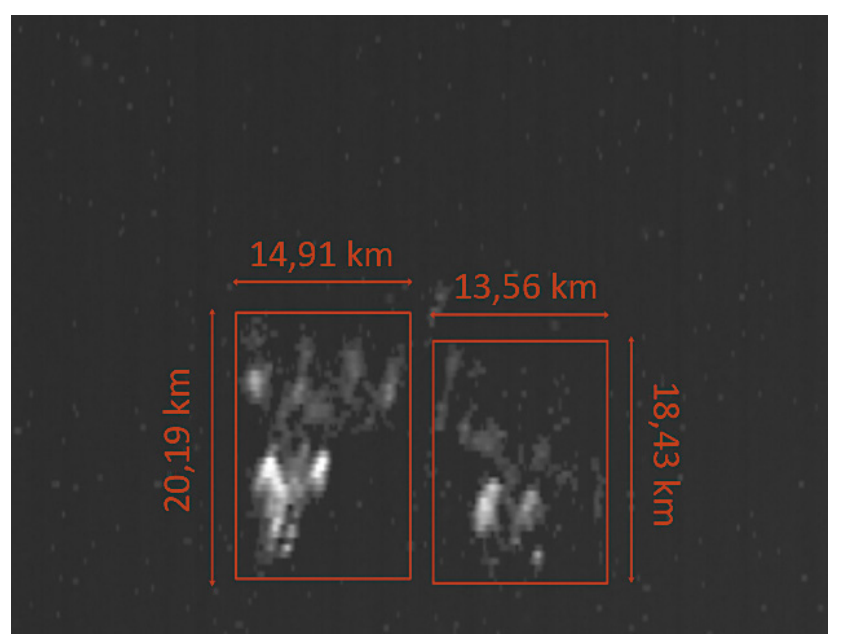

Figure 8: Sprites captured on 2017/05/31, at 22:03: 27.299 on frames 254 and 255

containing data on longitude, latitude and elevation in a KML friendly format. From there, the data was copied directly to the KML files, to map them in Google Earth.

For every observed sprite, the main points of interest were to determine the beginning and ending height, as well as the width of the sprite. This was done from the earlier calculated spatial positions of the points of interest.

The beginning and ending heights were simply read out from those calculations, whereas the length and width of the sprite were obtained from the basic distance significantly from sprite to sprite, this calculation was just meant to get a rough estimate, for which purpose this method proved to be sufficiently precise.

\section{Results and discussion}

On the night of 2017/05/31, 16 sprites were recorded by the camera in Rijeka and 9 by the camera in Višnjan. Of those, two single-station sprites captured at 21:46:18.781 and 22:03:27.299 from Rijeka were ana- 

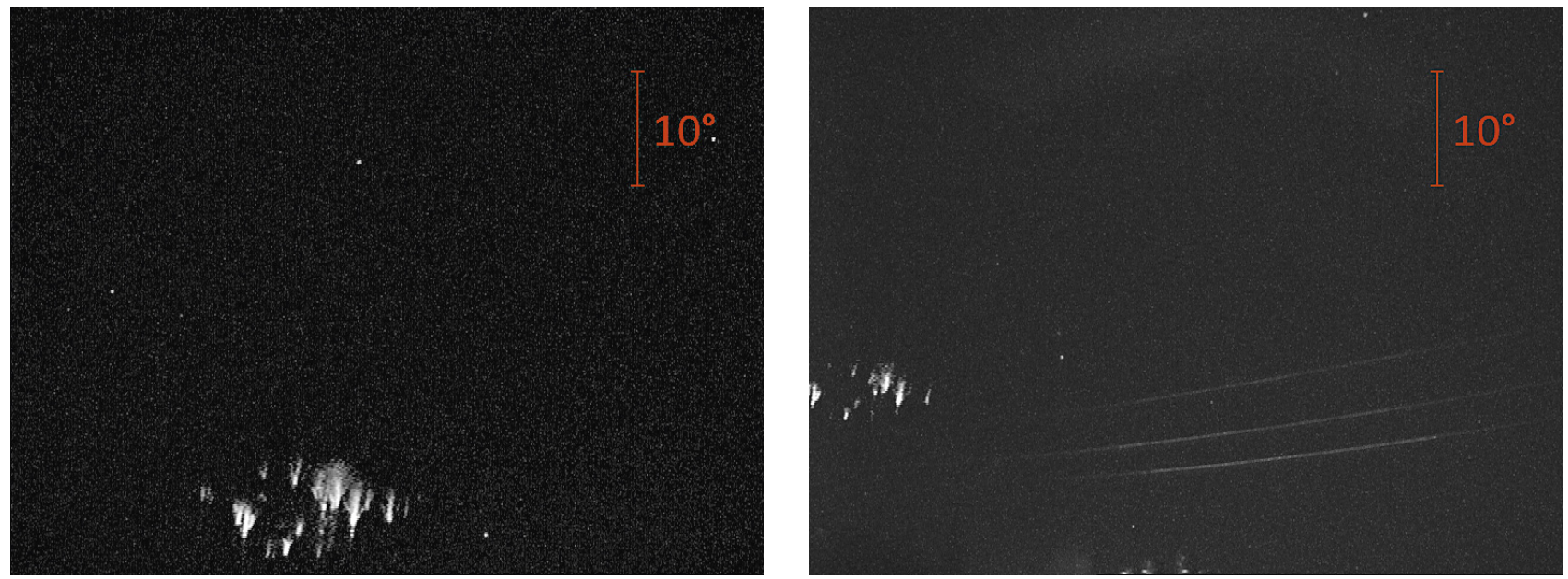

Figure 9: Images of the sprite recorded on 2017/05/31 at 21:57:44.376 from cameras in Rijeka (left) and Višnjan (right)

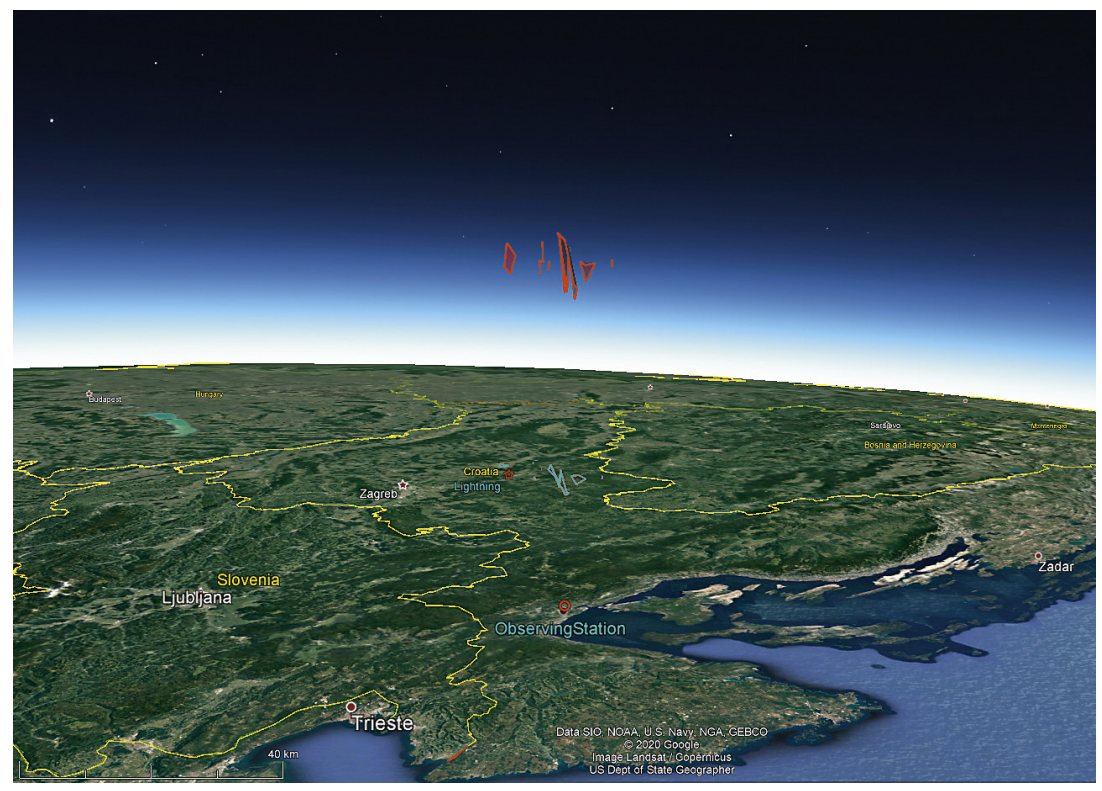

Figure 10: A Google Earth view of the position of the sprite recorded on 2017/05/31 at 21:57:44.376

lysed, as well as two double-station sprites captured at 21:57:44.376 and 22:07:16.440 from Rijeka and Višnjan.

\subsection{Single-station sprite analysis}

Sprites captured in Rijeka on 2017/05/31, at 21:46:18.781 on frames 50 and 51 are shown in Figure 5 and were analysed first. The program CMN_SpriteHeight_TLeSortGeocentric_AIJ was used separately for each detected sprite and the lightning detected at the corresponding time. For this particular sprite, there was only one lightning with the corresponding time. The obtained values can be found in Table 1 .

Figure 7 shows the sprites captured on 2017/05/31, at 22:03:27.299 on frames 254 and 255, which were included in a second analysis. It is interesting to note that in this particular case, there were 3 lightning strikes at the corresponding time. As there was no certain way to tell which lightning strike was the right one, the program CMN_SpriteHeight_TLeSort Geocentric_AIJ was used for all 3 of them and the average value was taken as the final result, with the maximal deviation being the error. The results are shown in Table 2.

The results show a minimum beginning height of 56.8 $\mathrm{km}$ and maximum ending height of $81.6 \mathrm{~km}$. The errors shown in the tables are all within $1 \mathrm{~km}$, however, it must be pointed out that the calculation for these single-station sprites is based on the assumption that the sprites originate exactly above the lightning, which turns out, is not generally the case (see Table 3, Table 4). This possible displacement which cannot be estimated from single-station observations introduces an additional error. Even having that in mind, these heights correspond almost perfectly to the ones found in literature (Bór, 2013). 


\subsection{Double-station sprite analysis}

The data obtained from sprites observed simultaneously by two cameras was processed using the lines of sight method to determine the 3D position of the sprites without using lightning data. Those 3D location results were then used to determine how far the sprite was from the most probable corresponding lightning.

The idea was to study the time delay of the sprite after the lightning, however, there was a surprising number of lightning strikes happening less than a second before the sprite. In some cases, it was impossible to choose the corresponding lightning with certainty, so this idea was abandoned for the moment and will be revisited when a larger database of observed sprites is available.

Another possible explanation as to why there are so many lightning strikes at the corresponding time is that a group of lightning strikes are in some cases responsible for creating sprites, instead of a single lightning strike. That, as well, may be the topic of a future study. Two double-station sprites from the same night were analysed in detail. In both cases, the beginning and ending heights of the sprites fall in the interval given in literature (Bór, 2013).

Besides sprite heights, the lateral distance of the sprite from its parent lightning was of interest. However, in the case of a group of sprites, it is unclear which point should be considered as the beginning point. To take this into account, in both analysed double-station sprites, three points were considered as the possible beginning point.

Table 3: Lateral distances between the lighting strikes and points of interest on the sprites recorded on 2017/05/31 at 21:57:44.376

\begin{tabular}{|l|l|l|l|}
\hline centre/km & bottom_1/km & bottom_2/km & $\begin{array}{l}\text { lightning } \\
\text { time delay/s }\end{array}$ \\
\hline 29.31 & 54.15 & 33.85 & 0.012 \\
\hline 37.31 & 62.29 & 41.77 & 0.062 \\
\hline 42.78 & 67.58 & 47.31 & 0.148 \\
\hline 9.693 & 27.56 & 12.66 & 0.217 \\
\hline 29.41 & 49.25 & 28.96 & 0.367 \\
\hline 19.66 & 43.45 & 24.28 & 0.396 \\
\hline
\end{tabular}

In both analysed cases, two distinct groups of sprites can be distinguished. This might not be obvious from the 2D images provided below as they lack depth perception, however, it is clear from the performed calculations.

The three points here considered to be potential beginning points of the sprite are the lowest points of each individual group of sprites on the image (labelled bottom_1 and bottom_2 in Tables 3 and 4), as well as the centre point of the group of sprites (labelled centre in Tables 3 and 4). The centre point was obtained by averaging the values of the top and bottom point, as well as the leftmost and rightmost point of the group of sprites.

As for the lightning, all lightning strikes that happened within the same second as the sprite appeared were taken as candidates for the sprite's corresponding lightning strike. The ones that happened before the sprite were taken out of consideration as it is considered that the sprite always comes after the lightning strike (Bór, 2013).

To properly visualise the selected points and see if they represent the images correctly, Google Earth was used. The first analysed sprite is presented on Figure 9 and it was recorded on 2017/05/31 at 21:57:44.376 from cameras in Rijeka and Višnjan. The heights of the recorded group of sprites range from $63.8 \mathrm{~km}$ to $85.7 \mathrm{~km}$.

The sprite location and the land projection are shown in Figure 10.

The next step was to calculate the distance from each lightning to each of the 3 points of interest. The results are shown in Table 3.

The same procedure was done for the sprite presented on Figure 11 which was recorded on 2017/05/31 at 22:07:16.440 from cameras in Rijeka and Višnjan. The camera from Rijeka captured the sprite on two frames. The heights of the recorded group of sprites range from $65.6 \mathrm{~km}$ to $81.4 \mathrm{~km}$.

The Google Earth image of the sprite and its land projection are shown in Figure 12.

The results of the distance calculations can be found in Table 4.

As mentioned before, it is hard to tell which lightning (or group of lightning strikes) corresponds to the observed sprites. Due to the sprite's irregular structure, it is
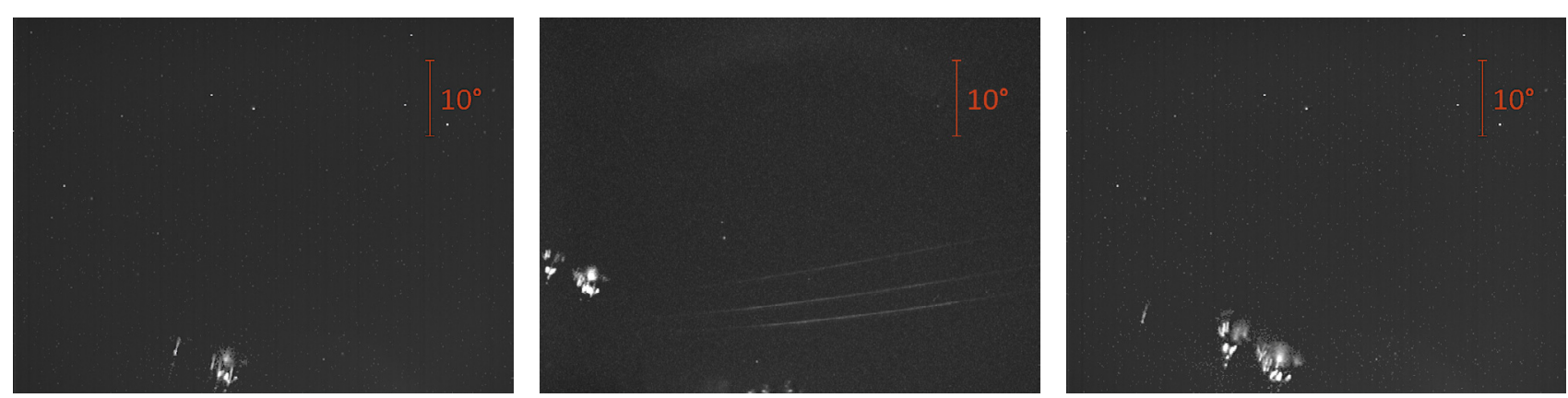

Figure 11: Images of the sprite recorded on 2017/05/31 at 22:07:16.440 from cameras in Rijeka (left \& center) and Višnjan (right) 

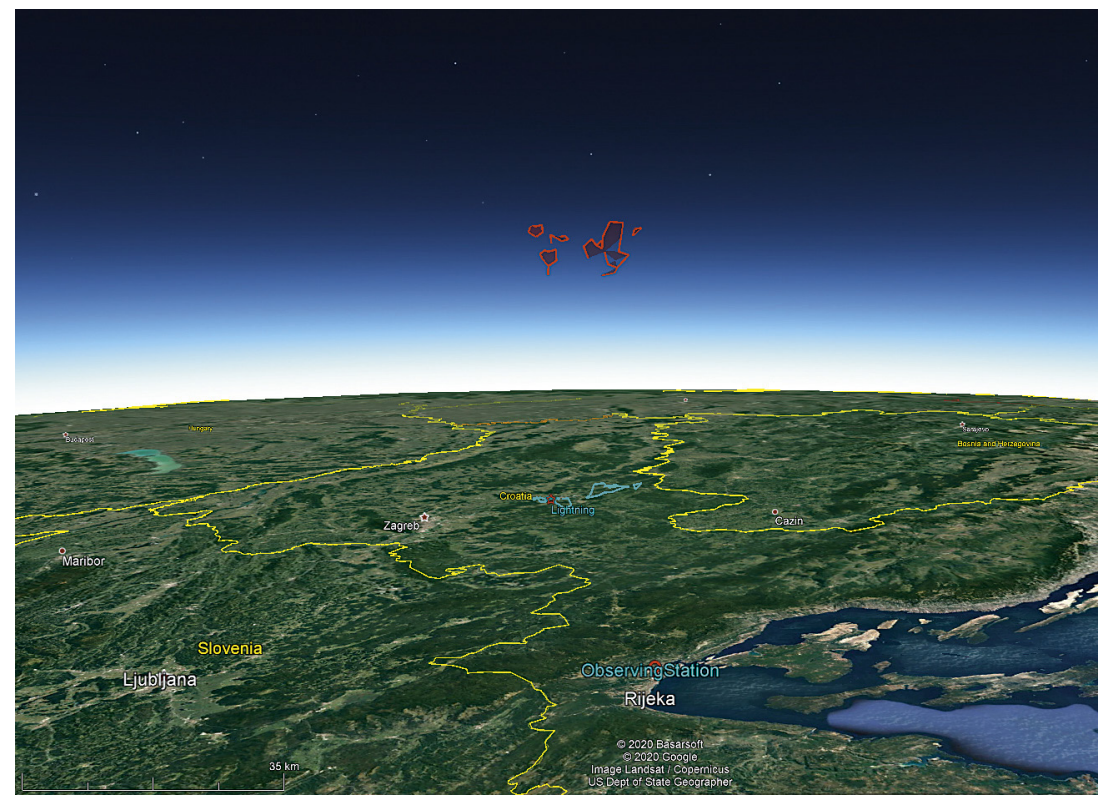

Figure 12: A Google Earth view of the position of the sprite recorded on 2017/05/31 at 22:07:16.440

open to discussion which point is to be considered as the beginning of the sprite. However, none of the points noted here, which could be considered the sprite's beginning, coincide with the position of any of the lightning strikes.

Considering these two cases consisted of groups of sprites, it feels the fairest choice of selection for the beginning of the sprites would be the middle point. In that case, the results show that the distance between the lightning strike and the corresponding sprites is anywhere from 10 to 40 kilometres.

For any choice of the bottom points of individual sprites as the beginning, the range is even larger. Another important consideration is that in both these cases, the angle between the cameras from which the sprites were captured was small (about $10^{\circ}$ ), which should be taken into account when discussing spatial error.

\subsection{Single vs. double-station analysis comparison}

Both sprite events simultaneously captured by CMN cameras and processed as double-station in the previous section were also analysed using the single-station analysis method. This provides a realistic insight on possible errors coming from assumptions made for single-station height estimation. The single-station error in height estimation is introduced by the lateral distance between the sprite and associated lightning, as well as the actual distance between the station and the sprite/lightning.

The sprite recorded on the night of 2017/05/31 at 21:57:44.376 was probably caused by a group of four lightning strikes, lying on the close range of azimuths as seen from both stations and cannot be assigned only to a single lightning strike. For this case, the single-station analysis provided beginning heights varying from 58.2
Table 4: Lateral distances between the lighting strikes and points of interest on the sprites recorded on 2017/05/31 at 22:07:16.440

\begin{tabular}{|l|l|l|l|}
\hline centre/km & bottom_1/km & bottom_2/km & $\begin{array}{l}\text { lightning } \\
\text { time delay/s }\end{array}$ \\
\hline 37.67 & 36.48 & 29.68 & 0.021 \\
\hline 30.50 & 20.43 & 35.23 & 0.131 \\
\hline 17.10 & 21.23 & 8.13 & 0.197 \\
\hline 17.02 & 20.91 & 8.47 & 0.430 \\
\hline
\end{tabular}

$\mathrm{km}$ to $68.1 \mathrm{~km}$ (compared to $63.8 \mathrm{~km}$ as calculated from double-station observations) and ending heights varying from $80.9 \mathrm{~km}$ to $93.9 \mathrm{~km}$ (compared to $85.7 \mathrm{~km}$ as calculated from double-station observations). The maximal differences compared to double-station analysis results are then $5.6 \mathrm{~km}$ and $8.2 \mathrm{~km}$. However, if average values resulting from all four lightning strikes are taken, maximal differences are reduced to only $1.1 \mathrm{~km}$ and $4.8 \mathrm{~km}$ in beginning and ending heights, respectively, which can be considered a very good estimation considering the fact that a group of lightning has been associated to a sprite.

The sprite recorded on the night of 2017/05/31 at 22:07:16.440 was attributed to a single lightning, based on small azimuth difference. The single-station results vary from $63.1 \mathrm{~km}$ to $63.3 \mathrm{~km}(65.6 \mathrm{~km}$ from doublestation) and $85.5 \mathrm{~km}$ to $90.4 \mathrm{~km}(81.4 \mathrm{~km}$ from doublestation) in beginning and ending heights, respectively. In this case, while the beginning heights are very consistent with the double-station result (a difference of only 2.5 $\mathrm{km}$ ), the $9.0 \mathrm{~km}$ error for the ending height of the sprite suggests that single-station results may suffer from significant errors. 
As can be seen from the results of the double-station analysis, the lateral distance between sprites and associated lightning for both cases turned out to be of great importance in height estimations from single-station observations. This leads to the conclusion that double-station observations are highly preferable over single-station ones.

The calculated heights and lateral distances are consistent with the ones published in (Lyons, 1996), which place the sprite heights in the $64 \mathrm{~km}$ to $88 \mathrm{~km}$ range, and lateral distances at $35 \mathrm{~km}$ to $40 \mathrm{~km}$ on average. Time delays between parent lightning and sprites are reported to have a distribution peak at 10-20 ms (Sao Sabbas et al., 2003) and $33 \mathrm{~ms}$ (Lyons, 1996), while both state that there are cases with significantly higher time delays, up to $300 \mathrm{~ms}$. All lightning strikes considered here in the single-station analysis fall within this range.

\section{Conclusion}

The proposed method for single sprite spatial locations proved effective as a rough estimate when observing sprites beginning in the vicinity of their corresponding lightning strike. Analysis of the double-station sprites showed that the observed sprites originate at least 10 kilometres away from the corresponding lightning. The results show that the distance could be up to more than 50 kilometres, however, the goal of this paper was not to find the interval of that distance, but rather to prove that the distance is not negligible.

More detailed studies are planned in the future involving a larger number of sprites, both single and doublestation, which may provide a better insight into displacements and delays between the lightning strike and the sprite occurrence. In case of such studies being made, the whole analysis process will most probably be automated.

\section{References}

Mlynarczyk, J., Bor, J., Kulak, A., Popek, M., Kubisz, J. (2015): An unusual sequence of sprites followed by a secondary TLE: An analysis of ELF radio measurements and optical observations. Journal of Geophysical Re-search: Space Physics, 120, 3, 2241-2254. https://doi.org/10.1002 /2014JA020780

Sentman, D. D., Wescott, E. M., Osborne, D. L., Hampton, D. L., Heavner, M. J. (1995): Preliminary results from the Sprites94 aircraft campaign: 1. Red Sprites. Geophysical Research Letters, 22, 10, 1205-1208. https://doi.org/ 10.1029/95GL00583

Heavner, M.J., Sentman, D.D., Moudry, D. R., Wescott, E.M. (2000): Sprites, Blue Jets, and Elves: Optical Evidence of Energy Transport Across the Stratopause. Geophysical Monograph Series, 123, 69-82. https://doi.org/10.1029/ GM123p0069

Bór, J. (2013): Optically perceptible characteristics of sprites observed in Central Eu-rope in 2007-2009. Journal of Atmospheric and Solar-Terrestrial Physics, 92, 151-177. https://doi.org/10.1016/j.jastp.2012.10.008
Stanley, M., Krehbiel, P., Brook, M., Moore, C., Rison, W., Abrahams, B. (1999): High speed video of initial sprite development. Geo-physical Research Letters, 26, 20, 3201-3204. https://doi.org/10.1029/1999GL010673

Stenbaek-Nielsen, H.C., Moudry, D.R., Wescott, E.M., Sentman, D.D., Sabbas, F.T.S. (2000): Sprites and possible mesospheric effects. Geo-physical Research Letters, 27, 23, 3829-3832. https://doi.org/10.1029/2000GL003827

Stenbaek-Nielsen, H.C., McHarg, M.G. (2008): High timeresolution sprite imaging: observations and implications. Journal of Physics Applied Physics, 41, 23, 234009, 14. https://10.1088/0022-3727/41/23/234009

Hardman, S.F., Dowden, R.L., Brundell, J.B., Bahr, J.L., Kawasaki, Z., Rodger, C.J. (2000): Sprite observations in the Northern Territory of Australia. Journal of Geophysical Research, 105, 4, 4689-4697. https://10.1029/1999JD 900325

Wescott, E.M., Sentman, D.D., Heavner, M.J., Hampton, D.L., Vaughan, O.H., (1998): Blue Jets: their relationship to lightning and very large hailfall, and their physical mechanisms for their production. Journal of Atmospheric and Solar-Terrestrial Physics, 60, 7-9, 713-724. https://10.1016/ S1364-6826(98)00018-2

Malagón-Romero, A., Teunissen, J., Stenbaek-Nielsen, H. C., McHarg, M. G., Ebert, U., Luque, A. (2020): On the emergence mechanism of car-rot sprites. Geophysical Research Letters, 47, 1. https://10.1029/2019g1085776

Andreić, Ž., Šegon, D. (2008): The first year of Croatian Meteor Network. In Proceedings of the International Meteor Conference, Sachticka, Slovakia, 18-21 September 2008, edited by Kaniansky S. and Zimnikoval P. Hove, Belgium: International Meteor Organization, 16-23. https://ui. adsabs.harvard.edu/abs/2010pim8.conf...16A/abstract

Vida D., Šegon D., Gural P., Martinović G., Skokić I. (2014): CMN_ADAPT and CMN_binViewer software. Proceedings of the International Meteor Conference, Giron, France, ISBN 978-2-87355-028-8, 59-63. http://cmn.rgn. $\mathrm{hr} /$ downloads/papers/IMC_2014_vida_cmn_adapt.pdf

Šegon, D. (2009): How many stars are needed for a good camera calibration? WGN, Journal of the International Meteor Organization, 37, 3, 80-83. http://articles.adsabs.harvard. edu/full/2009 JIMO...37...80S

Borovicka, J. (1990): The Comparison of Two Methods of Determining Meteor Trajectories from Photographs, Bulletin of the Astronomical Institute of Czechoslovakia, vol. 41, p.391. https://ui.adsabs.harvard.edu/abs/1990BAICz..41.. 391B/abstract

Walter A. Lyons (1996): Sprite observations above the U.S. High Plains in relation to their parent thunderstorm systems, Journal of Geophysical Research, vol. 101, no. D23, pages 29,641-29,652, https://doi.org/10.1029/96JD01866

Sao Sabbas et al. (2003): Statistical analysis of space-time relationships between sprites and lightning, Journal of Atmospheric and Solar-Terrestrial Physics 65 (2003) 525 535, https://doi.org/10.1016/S1364-6826(02)00326-7

\section{Internet sources:}

URL: http://www.lightningmaps.org/blitzortung/europe/ (accessed 28 February 2020) 


\section{SAŽETAK}

\section{Analiza vatrenjaka iz opažanja Hrvatske meteorske mreže}

Rad predlaže novu metodu analize vatrenjaka opaženih sa samo jedne stanice, koristeći se pozicijom munje kako bi se odredio prostorni položaj vatrenjaka. Valjanost metode provjerena je određivanjem visina vatrenjaka. Dobiveni rezultati podudaraju se s rezultatima koje su prethodno objavili drugi autori. Udaljenost vatrenjaka od odgovarajuće munje izmjerena je za vatrenjake opažene s dviju stanica istodobno te nije zanemariva.

\section{Ključne riječi:}

vatrenjaci, osvjetljenje, kratkotrajni svjetlosni događaji

\section{Authors contributions}

Marko Šegon (mag. phys.): extracted lightning data from the blitzortung website, selected and analysed points of interest in AstroImageJ. Maria Vukić (mag. phys.): Selected and analysed points of interest in AstroImageJ, edited the python program to give KML-friendly output. Damir Šegon: Provided data for analysis, made Google Earth visualisations of the sprites. 